\section{DIREITO AO LAZER E DIREITO À CIDADE: INTERSEÇÕES A PARTIR DE UM PROJETO DE EXTENSÃO UNIVERSITÁRIA}

\author{
THE RIGHT TO LEISURE AND THE RIGHT TO THE CITY: INTERSECTIONS IN A \\ UNIVERSITY OUTREACH PROJECT
}
DERECHO AL OCIO Y DERECHO A LA CIUDAD: INTERSECCIONES DE UN PROYECTO DE EXTENSIÓN UNIVERSITARIA

Wecisley Ribeiro do Espírito Santo*, Jeferson José Moebus Retondar*

\section{Palavras chave:} Atividades de lazer. Esportes.

Planejamento de cidades.

Direitos humanos.
Resumo: 0 artigo apresenta um relato sobre um projeto de extensão universitária que visa articular direito ao lazer e direito à cidade. Pressupostos teóricos foram buscados no urbanismo e nas teorias críticas da Educação Física - com foco especial na distribuição assimétrica do lazer pelos territórios urbanos. As escolhas metodológicas também buscam uma síntese entre pesquisa etnográfica e extensão universitária, radicalizando as potencialidades itinerantes das práticas de lazer. A conclusão faz um balanço dos malogros e êxitos do processo.
Keywords:

Leisure activities.

Sports.

City planning.

Human rights.

\begin{abstract}
This paper describes a community outreach project aimed at connecting the right to leisure and the right to the city. Theoretical assumptions were sought in urban planning and Physical Education critical theories - focused on the asymmetric distribution of leisure by urban territories. Methodological choices also sought a synthesis between ethnographic research and university outreach programs, radicalizing the itinerant potentials of leisure practices. The conclusion takes stock of failures and successes of the process.
\end{abstract}

Palabras clave: Actividades de ocio. Deportes.

Planificación de ciudades.

Derechos Humanos.
Resumen: El artículo presenta un relato sobre un proyecto de extensión universitaria para articular el derecho al ocio y el derecho a la ciudad. Las premisas teóricas se buscaron en el urbanismo y en las teorías críticas de la Educación Física - con especial énfasis en la distribución asimétrica de los espacios de ocio en zonas urbanas. Las elecciones metodológicas también buscan una síntesis entre investigación etnográfica y extensión universitaria, radicalizando las potencialidades itinerantes de las actividades de ocio. La conclusión hace un balance de los fracasos y éxitos del proceso.
**Universidade do Estado do Rio de Janeiro. Rio de Janeiro, RJ, Brasil. E-mail:wecisley@gmail.com; retondar@oi.com.br

Recebido em: 12-09-2016 Aprovado em: 06-02-2018

DOI: http://dx.doi.org/10.22456/1982-8918.67920 (c) (1) (3) Licence 


\section{INTRODUÇÃO}

"A arte tem o poder de re-encantar a cidade". (Henri Lefebvre).

Este artigo compreendeum relatosobre a implantação prática de um projeto de interiorização da extensão universitária, formulado pelo Núcleo dePesquisa Lazerem Observação nas Cidades (LOCI), vinculado ao Laboratório de Imaginário Social sobre Atividades Corporais e Lúdicas (LISACEL), com sede no Instituto de Educação Física e Desportos/UERJ. Trata-se de um esforço para encontrar interseções entre esporte comunitário, corporeidade e direito à cidade, com vistas à promoção do desenvolvimento humano.0 problema que abordamos no que se segue pode ser expresso sob a forma da seguinte indagação: o caráter essencialmente itinerante de certas atividades esportivas, lúdicas e artísticas - tais como torneios, competições, mostras, festivais -pode ser aproveitado com intencionalidade formativa para o exercício ativo do direito à cidade? Em termos mais específicos, a experiência de circulação e ocupação do espaço urbano e seus equipamentos públicos de lazer, por parte de jovens residentes de territórios segregados da cidade, com fins predominantemente lúdicos, pode concorrer para a formação da sua consciência relativa ao direito à cidade? A hipótese que sustentávamos, por ocasião do planejamento e das primeiras ações do projeto ora relatado, compreendia uma resposta afirmativa a essas indagações. Destarte, o presente artigo pode ser concebido como um balanço preliminar da eficácia dessa hipótese de trabalho. Vale iniciar, pois, com algumas palavras sobre as questões sociais que constituem objeto de nossa preocupação.

O regime mundial contemporâneo de produção das cidades tem se organizado com base na economia de mercado (HARVEY, 2014; HARVEY, 2008). No âmbito da política habitacional, ora de modo absoluto, ora relativamente, os principais gestores da produção e distribuição territorial de habitações de interesse social são amiúde as empreiteiras, construtoras e incorporadoras privadas (MARICATO, 2013). No que se refere ao financiamento, conquanto por vezes exista subsídio público, é o mercado financeiro que fornece o modelo de execução do orçamento habitacional (HARVEY, 2014).

Temos, portanto, diante de nós, um paradoxo: habitações de interesse social, geridas e produzidas pelo grande capital urbano e bancário. Esse processo faz com que a seleção dos terrenos, dentre as opções possíveis no interior dos bancos de terra privados, concentre-se nas regiões mais distantes dos centros, desprovidas de infraestrutura e equipamentos necessários à reprodução da vida dos trabalhadores urbanos (MARICATO, 2013; HARVEY, 2014).

As contradições aí presentes foram descritas, em 1968, no seminal, Le droit à la ville, de Henri Lefebvre. Na ocasião,o autor traçou os contornos da oposição marxiana entre valor de uso e valor de troca, aplicada à produção do espaço. Disso decorreu a leitura que se tornou clássica no urbanismo entre cidade como obra (que encontra seu modelo arquetípico na obra de arte - expressão de necessidades humanas), de um lado, e cidade como produto (submetida ao fetichismo da mercadoria e desprovida de suas propriedades úteis), de outro.

Esse modelo teórico permanece útil para entender porque habitações de interesse social não apenas não atendem a esse interesse mesmo como, pior, aprofundam as questões sociais quepretendem solucionar (MARICATO, 2013; PANDOLFI; ESPÍRITO SANTO, 2014; ESPÍRITO SANTO, 2015). Eis o que ocorre hoje nas cidades da região serrana fluminense, onde o programa Minha Casa Minha Vida ${ }^{1}$ tem sido destinado às vítimas do desastre climático de janeiro de 2011. O bairro Terra Nova (maior conjunto habitacional da região, construído depois da tragédia) condensa todos os dilemas inventariados acima. Localizado na extrema 
periferia de Nova Friburgo, esse conjunto de sete condomínios abriga cerca de 8.000 pessoas, com acesso limitado a escolas, unidades de saúde, creches, equipamentos culturais e de lazer e transporte coletivo. Eis o contexto que confere relevância ao projeto de extensão ora relatado.

Um princípio fundamental do projeto diz respeito à interiorização das ações extensionistas. Trata-se de um esforço coletivo e institucional da UERJ, no sentido de levar o conhecimento universitário aos territórios dos quais ele se encontra mais afastado, sendo, por conseguinte, onde se faz necessário um diálogo horizontal e colaborativo entre saber acadêmico e epistemologias populares. Pretendeu-se, desde as primeiras ações, aproveitar o conhecimento disponível acerca do lazer, do esporte e da corporeidade humana para a elaboração de práticas com pretensão de, senão garantir o direito à cidade a jovens segregados dos centros urbanos - 0 que depende de variáveis macrossociais e econômicas, somente alteráveis por meio de mobilização popular e políticas públicas profundas -, ao menos ensejar algumas experiências urbanas formativas de hábitos e consciências informadas pelo mesmo direito. Em termos concretos, buscamos, na medida de nossas possibilidades, vitalizar a vida lúdica de um bairro periférico, de um lado, e conectar esse território às competições, encontros, mostras e festivais artísticos, existentes na cidade, de outro. 0 município escolhido para implantação do projeto foi Nova Friburgo. Primeiro, por conveniência, já que os coordenadores residem na região serrana do Rio de Janeiro; um em Petrópolis, outro na própria Nova Friburgo. Em seguida, por conta da presença do campus da UERJ, neste município, que conta com um complexo de lazer, com três quadras poliesportivas, piscina e anfiteatro - sendo, pois, um equipamento público de lazer estratégico.

\section{BASES TEÓRICAS}

Contra o desencantamento produzido pela subsunção do valor de uso ao valor de troca, na produção do espaço urbano, diz Lefebvre, "a arte tem o poder de re-encantar a cidade". Diante de uma dinâmica de mercado que converte as cidades em produtos, importa ocupar o espaço público com arte para reconstituí-lo como obra. Este artigo sugere que, tal como a arte, o esporte - organizado sob uma perspectiva do esporte comunitário e não do esporte espetáculo, bem entendido - tem o poder de re-encantar as cidades. Trata-se de chamar a atenção para o fato de que a ocupação do espaço público para práticas esportivas, culturais e lúdicas constitui um antídoto eficaz contra a privatização desses espaços, bem como uma estratégia possível para a produção de coesão social. A reflexão sobre a contribuição particular do esporte, do lazer e da Educação Física para a revitalização do espaço urbano constitui 0 primeiro moteteórico deste projeto.

O segundo argumento refere-se à corporeidade humana. 0 corpo, pelo menos desde a fenomenologia da percepção de Maurice Merleau-Ponty (1980), é o cerne epistemológico da cognição; mas, também, a superfície afetiva da sensibilidade humana. Para Merleau-Ponty, o sujeito não possui um corpo, ele é um corpo: autoposse indivisível que sintetiza a história de vida. Os movimentos desse corpo são pistas, marcas reveladoras dabiografia do sujeito que se apresenta sob a forma de atos. Assim, uma criança que chuta uma bola ou que vibra com um soco no ar por conta de um gol feito não chuta com os pés e não soca com as mãos, mas chuta a bola e soca o ar com e de corpo inteiro; com a encarnação de sua subjetividade, de sua história de vida e de seu enraizamento na prática que o possibilitou expressar aquilo que só é possível ser dito por intermédio dos gestos. 
Embora para os profissionais da área seja desnecessário justificar a evocação da estética e da arte como objeto de intervenção pedagógica em Educação Física - já que pelo menos desde os anos 1990 estes componentes foram incluídos no acervo da cultura corporal de movimento e, portanto, como objeto desta disciplina -, vale a pena remeter o leitor não especializado às chamadas abordagens teóricas deste campo². Mais recentemente, um número considerável de trabalhos tem se destacado na articulação entre arte, cultura e esporte (MELO, 2009; REIS; CAVICHIOLLI, 2009; ALVES, 2009; SOARES; MADUREIRA, 2005). Vale evocar elementos genealógicos anteriores desta relação entre Educação Física e arte. Por exemplo, na metáfora poética de 1915, formulada por Fernando de Azevedo para se referir à gymnástica, "[...] a poesia do corpo" (AZEVEDO, 2015). Esta metáfora, como de resto os trabalhos inventariados, nos remete a uma indistinção primordial entre arte, esporte, experiência estética e corporeidade. Trata-se de considerar seriamente uma profícua interpretação que abre o clássico Homo ludens, de Huizinga (1955): entre os jogos agonísticos da arena olímpica, passando pelas lutas de recitações poéticas do teatro, até as competições filosóficas da acrópole, na Grécia antiga, não há uma diferença de natureza ou estrutura, mas apenas de grau (de sublimação, para empregar o conceito freudiano). Trata-se, em todos os casos, diz Huizinga, de manifestações de um mesmo impulso humano básico para conferir formas ordenadas à experiência; um impulso estético. A possibilidade de vivenciar esses múltiplos gêneros de experiência estética (esportivas e artísticas) constituiria, pois, um laboratório para a formação das sensibilidades, frequentemente pouco disponível em territórios urbanos segregados.

Finalmente, nossa terceira hipóteserefere-se à relação entre direito ao lazer e direito à cidade. A mobilidade urbana, ao propiciar acesso à cidade, enseja circulação de pessoas, culturas, classes, etnias, gerações, o que pode se contrapor aos processos de segregação. O caráter itinerante tanto das competições esportivas quanto dos espetáculos artísticos pode constituir uma porta de acesso à cidade e seus bens culturais. A hipótese central deste projeto - formulada a partir de uma síntese teórica entre os pesquisadores do direito à cidade (HARVEY, 2014; MARICATO, 2013; LEFEBVRE, 1968), de um lado, os pensadores que se dedicaram à experiência sensorial (MARLEAU-PONTY, 1980; PIAGET $^{3}, 1983$ ) e à educação estética (MELO, 2009; SCHILLER, 2002), de outro, e finalmente, os observadores da relação entre esporte, corpo e educação (RETONDAR et al., 2007; ESPÍRITO SANTO; CUPOLILLO, 2005) - é que a educação corporal e esportiva pode se articular, e, mais que isso, viabilizar a mobilidade urbana e o acesso a equipamentos de lazer, dada a mobilidade das competições esportivas e dos bens culturais vinculados à cultura corporal (BRACHT et al., 1992) - mostras/ oficinas/espetáculo de dança, performances, teatrais, etc.

\section{DECISÕES METODOLÓGICAS}

Às escolhas teóricas inventariadas soma-se outra, de caráter metodológico, qual seja, a opção pelo registro etnográfico como meio de articular pesquisa e extensão. Etnografia e extensão é outra forma de falar de pesquisa-ação.Os procedimentos de pesquisa consistiram no registro em caderno de campo das dinâmicas sociais observadas, ao longo de todo 0

2 São exemplos delas a abordagem crítico-superadora (BRACHT,etal., 1992), a abordagem crítico-emancipatória (KUNZ, 1994), a abordagem construtivista-interacionista (FREIRE, 1989), a abordagem sistêmica (BETTI, 1991), a abordagem culturalista (DAOLIO, 1995). Todas essas propostas conferem centralidade à noção de cultura para a prática pedagógica em Educação Física.0 aproveitamento dos achados da Sociologia e da Antropologia aproximam o presente artigo das abordagens de Betti e Daolio. 
processo de implementação do projeto. A releitura sucessiva das anotações de campo nos permitiu inventariar os aspectos mais importantes da experiência para compor a estrutura do presente artigo. Queremos aproveitar as potencialidades formativas da relação entre lazer e direito à cidade,implementando escolinhas esportivas,tornando-as itinerantes e fazendoas perpassar pelos equipamentos urbanos de lazer do município, de um lado, agregando a perspectiva da educação estética por meio de outros bens ligados à cultura corporal, de outro, e finalmente, possibilitando visitas periódicas dos jovens participantes do projeto aos campi da UERJ, entendida como um equipamento estratégico. Em termos concretos, os procedimentos metodológicos adotados podem ser sintetizados em duas etapas, que correspondem a escalas geográficas que se distinguem entre si por níveis de abrangência.

a) Intervenção pedagógica, no âmbito de territórios segregados de Nova Friburgo, por meio de escolinhas esportivas, articulada a um trabalho de assessoria técnica no sentido de colaborar com os moradores em seu processo de auto-organização. Trata-se, por um lado, de aproveitar a materialidade dos próprios locais de moradia para a elaboração de opções esportivas e de lazer e, por outro lado, de disponibilizar o conhecimento acadêmico como ferramenta auxiliar na constituição de associações, mutirões, na formulação de projetos para captação de recursos em editais públicos em benefício da produção local de equipamentos culturais e de lazer. Pode-se sumariar metaforicamente que esta primeira etapa intenta - dentro dos limites de um projeto de interiorização da extensão universitária - levar a cidade ao bairro.

b) Circulação itinerante das escolinhas, perpassando pelos equipamentos públicos de lazer disponíveis em diversas regiões de Nova Friburgo. Trata-se de viabilizar o uso dos locais públicos reservados ao esporte e ao lazer existentes na cidade. Assim, de um lado, essas escolinhas e oficinas se tornam elas mesmas móveis, ensejando 0 acesso dos jovens do projeto a múltiplos equipamentos urbanos e, de outro, aproveita-se mais sistematicamente os eventos públicos (esportivos e artísticos) oferecidos na vida cultural e lúdica do município, como meio de formação desses jovens. Esta segunda etapa pretende, pois, levar jovens submetidos à segregação urbana a romper as fronteiras simbólicas que os separam das regiões mais bem equipadas da cidade.

\section{ANÁLISE E DISCUSSÃO}

A implementação prática da primeira fase idealizada não logrou êxito. As atividades se concentraram em escolinhas de futebol de várzea, no bairro Terra Nova. A opção por essa modalidade se construiu de modo participativo. A entrada em campo foi viabilizada pelo síndico do Condomínio II, previamente conhecido de um dos coordenadores do projeto. Foi esse síndico quem marcou uma reunião de planejamento com os coordenadores, junto com as crianças e jovens interessados em participar do que então foi tratado, em termos êmicos, como "um projeto de esporte para o condômino". Durante a reunião, ficou claro para os coordenadores que o futebol compreendia a modalidade preferida entre as crianças e jovens presentes. Por outro lado, e complementarmente, não havia no condomínio espaços disponíveis adequados a modalidades esportivas múltiplas, mas apenas um pequeno campinho de várzea, construído pelas próprias crianças.

Se o caráter precário dos equipamentos de lazer, em particular, e dos equipamentos públicos urbanos, em geral, nestes territórios segregados da cidade constituíram o motor 
para a formulação deste projeto, durante sua implementação prática fomos nós mesmos, os acadêmicos, que tivemos a oportunidade de sentir os limites materiais que isso impõe à tentativa de contribuir para a promoção do direito ao lazer, nesses locais. À dificuldade de viabilizar transporte público ${ }^{4}$ para a concretização das atividades itinerantes somou-se a inviabilização do trabalho no campinho, durante o período chuvoso do verão.Por seu turno, a "churrasqueira", um dos poucos espaços cobertos disponíveis tinha seu uso bastante disputado, entre os moradores, nesse condomínio de escassos equipamentos lúdicos.Seguiu-se, a partir de março, a longa greve de cinco meses da UERJ e, para completar o quadro de frustração das nossas expectativas, a escassez de editais de financiamento a projetos, motivada pelo subterfúgio da crise econômica ${ }^{5}$ do Estado. Isso nos forçou a um redirecionamento do local do projeto. Passamos a sediar o trabalho em uma escola da rede pública de educação do município com o objetivo de aproveitar a infraestrutura mínima de lazere a colaboração dos professores.O que, entretanto, não significou menores dificuldades. Como já veremos, esses equipamentos são marcados pela precariedade radical.

Por cerca de dois anos a professora de Educação Física de uma escola estadual do São Geraldo 6 em vão abordou o diretor da unidade reivindicando a aquisição de material esportivo e de lazer para a escola. Tratava-se, pois, de demanda por recursos pedagógicos específicos para as aulas dessa disciplina curricular. Tendo sido a legitimidade de suas solicitações reconhecida pelo diretor, o material, contudo, nunca chegou. E, no entanto, a ausência de material pedagógico para a Educação Física não decorria apena sda histórica insuficiência do orçamento escolar - investido em tecnologias (Datashow, televisões, computadores, etc.) -, mas de prioridade conferida a recursos cujos usos (conquanto imprescindíveis ao trabalho educacional) supõem imobilidade corporal dos alunos. Não dispomos de espaço para aprofundar a relação entre dispositivos digitais e imobilidade corporal. Vale notar, entretanto, com o filósofo italiano Franco Berardi (2005), que a digitalização das relações sociais, ensejada pelo predomínio das Ferramentas de Comunicação e Informação contemporâneas, tem produzido um processo complementar de "descorporalização" das relações sociais. No entender de Berardi, esta dinâmica se acompanha de um aumento de mal-estar e depressão que se relaciona com uma hiperestimulação sensual e um déficit de oportunidades corporais concretas para saciar estes estímulos. No campo esportivo uma evidência desse processo pode ser identificada no declínio das práticas esportivas comunitárias ${ }^{7}$, acompanhado docrescimento exponencial dos jogos digitais. No nosso entendimento, a Educação Física deveria enfatizar a relevância antropológica da prática corporal concreta de atividades lúdicas, em detrimento da digitalização do lazer levada ao paroxismo; como de resto, combater o formalismo abstracionista predominante nas escolas brasileiras, por exemplo, evitando excessivas aulas teóricas.

O primado dos dispositivos de imobilidade corporal em detrimento de material esportivo e de lazer assumiu um estado objetivado na própria materialidade do prédio escolar. A unidade

\footnotetext{
4 No projeto de extensão, registrado no Departamento de Extensão da UERJ, prevíamos a possibilidade de aproveitar os ônibus da própria universidade para viabilizar o acesso dos jovens aos equipamentos urbanos de lazer; o subterfúgio da crise financeira inviabilizou este intento, sob alegação de falta de combustível e motoristas.

5 A expressão "subterfúgio da crise", que empregamos neste trabalho, inspira-se em prodigiosa bibliografia que sugere ser 0 alegado "desequilíbrio fiscal" do Estado o resultado de um sistema de drenagem do fundo público para o mercado financeiro, produzido deliberadamente por políticas de governo orientadas em benefício de interesses rentistas, por exemplo, Fattorelli (2013).

6 Bairro de Nova Friburgo majoritariamente habitado por membros das classes trabalhadoras friburguenses e distante do centro urbano municipal cerca de $5 \mathrm{~km}$.

7 Processo, por seu turno, também relacionado com a diminuição dos espaços públicos disponíveis, nas periferias das grandes e médias cidades, em um processo de urbanização desordenada e primado absoluto do transporte individual privado - o qual subtraiu os campos de várzea não em benefício dos equipamentos públicos de lazer, mas de rodovias e estacionamentos.
} 
não dispõe de espaço adequado à prática da Educação Física a não ser um pequeno pátio de terra batida - sem recursos estruturais garantidores da acessibilidade de alunos com deficiência. Há um pátio revestido com calçamento no qual a direção mandou construir uma série de mesas e bancos de alvenaria, com o intuito deliberado de que o espaço não fosse empregado para práticas esportivas, que pudessem perturbar a ordem das salas de aulas contíguas. Neste contexto, o único equipamento de lazer disponível é uma mesa de alvenaria própria para tênis de mesa.

Cabe aqui uma pequena digressão para esclarecer a relação que nos parece existir entre lazer e Educação Física, como de resto, entre as infraestruturas materiais de ambos. Nossa orientação teórica supõe que Educação Física e lazer - bem como material didático da Educação Física e equipamento de lazer - conquanto não constituam a mesma coisa, são homólogos que variam apenas em sua escala. Nesse sentido, a cidade (e sua dimensão educadora ambígua) está para a escola como os equipamentos urbanos de lazer estão para o material e infraestrutura de lazer escolar, e como o lazer na vida social mais geral está para a Educação FísicaEscolar. Perfilhamos o postulado teórico segundo o qual a Educação Física deve buscar inspiração no sentido original do grego Skole - qual seja, lazer, tempo liberado do trabalho. Nesse sentido, parece-nos, a intervenção pedagógica desta disciplina deveria não apenas evitar o sentido aversivo orientador do trabalho $0^{8}$ escolar, senão também reativar a contiguidade semântica entre lazer, recreação e educaçã $0^{9}$.

Feito 0 adendo, voltemos ao relato.A materialidade da escola mencionada, com a primazia conferida aos equipamentos estimuladores da imobilidade, é apenas uma expressão, em escala reduzida, da materialidade mais ampla do próprio bairro. Certa vez, a professora mencionada sugeriu aos alunos a realização de uma pesquisa dividida em duas partes:

a) um inventário dos equipamentos públicos de lazer existentes no bairro (que se resumem a uma única quadra poliesportiva em péssimo estado de conservação), e

b) realização de entrevistas com os moradores do São Geraldo com o objetivo de coletar sugestões de equipamentos públicos de lazer para o bairro a serem reivindicados ao poder público.

Ao contrário do que se poderia esperar, a reivindicação prioritária dos entrevistados não se referiu a parquinhos para as crianças, ciclovias, pistas de skate, academia pública de ginástica. A maior parte das pessoas ouvidas desejava antes a construção de uma pracinha para a sociabilidade dos moradores. Ora, o que o caráter modesto das reivindicações expressa é a negligência do Estado com relação à garantia do lazer como direito social, que sonega a bairros como o São Geraldo equipamentos tão elementares quanto uma praça pública ${ }^{10}$.

Foi nesse contexto, de um território que leva ao paroxismo a sonegação do lazer aos seus moradores, que nosso projeto, em parceria com a professora acima mencionada

\footnotetext{
8 Do latim, tripalium, um instrumento de tortura.

9 “A palavra 'escola' tem uma história curiosa atrás de si. Significando originariamente 'lazer' ela adquiriu hoje o sentido precisamente oposto de trabalho sistemático e treinamento, na medida em que a civilização restringe crescentemente o livre usufruto do tempo dos jovens e conduz classes de jovens cada vez mais numerosas a uma severa disciplina desde a infância" (HUIZINGA, 1955, p. 148).

10 A literatura sobre o uso social das praças públicas é prodigiosa e não podemos explorá-la aqui. Vale registrar, no entanto, o trabalho pioneiro de JanesJacobs de 1961. Depois de apontar para a contiguidade semântica e urbanística entre os conceitos de praças e parques públicos, ela se encaminha para combater a concepção essencialista, segundo a qual uma praça tem invariavelmente um efeito positivo sobre a vida pública: "Espera-se muito dos parques urbanos. Longe de transformar qualquer virtude inerente ao entorno, longe de promover as vizinhanças automaticamente, os próprios parques de bairro é que são direta e drasticamente afetados pela maneira como a vizinhança neles interfere" (JACOBS, 2011, p. 72). A demanda enfática por uma praça, por parte dos moradores do bairro São Geraldo, poderia ser tomada como um indicador de sua provável (e incerta) relevância, naquele território específico.
} 
e com o Serviço Social do Comércio de Nova Friburgo ${ }^{11}$ (SESC-NF), se instalou. Doravante, aproveitando a infraestrutura fornecida pelo SESC, nos concentramos em escolinhas de iniciação esportiva na modalidade badminton. Nos convertemos, pois, em colaboradores adicionais, na parceria SESC-escola. Nosso papel consistiu, sobretudo, em inventariar eventos e competições de badminton, acompanhar os alunos e a professora, nas circulações urbanas que se seguiram, além de cooperar nas aulas. $O$ aproveitamento deste processo para realização de pesquisa etnográfica, com registro em caderno de campo das dinâmicas sociais observadas com o decorrer da interação com os alunos, foi de grande valor heurístico para repensarmos a relação entre esporte, lazer e direito à cidade.De fato, poder-se-ia dizer que nossa intervenção interinstitucional protagonizou umatransformação importante na sociabilidade comunitária do São Geraldo. Um primeiro aspecto interessante a este respeito foi a adesão quantitativamente superior dos alunos se comparada com outros bairros (melhor equipados com recursos de lazer, onde também realizamos pesquisa de campo) nos quais o mesmo projeto foi implementado - eis a razão pela qual essa localidade foi tomada como um caso privilegiado para pensar a relação entre lazer e direito à cidade. Para além dos efeitos secundários do projeto - a respeito dos quais as críticas que denunciam o caráter ideológico das modalidades heterônomas de legitimação do esporte nos parecem válidas (OLIVEIRA, 2010) - sobre o desempenho escolar dos alunos - diminuição do absenteísmo e da evasão escolar, por um lado, melhora das notas por parte de alguns poucos alunos, por outro $^{12}$-, interessa, para os propósitos deste projeto, os efeitos sociabilizadores transversais que dele decorreram. Por conta dele os alunos participantes passaram a ter maior acesso às áreas melhor equipadas do espaço urbano, mediante a participação em eventos e competições esportivaspreviamente existentes no calendário esportivo da cidade. Em termos concretos, estes alunos começaram a frequentar as instalações do próprio SESC-NF, com sua multiplicidade de materiais esportivos e de lazer ${ }^{13}$.Nesse mesmo sentido, frequentam doravante também as escolas com melhorinfraestrutura que a sua; participam agora dos eventos públicos de lazer, sediados no Centro urbano municipal.

As implicações destas novas experiências socioculturais dos alunos do projeto não são triviais. Se, por um lado, a iniciação ao badminton proporcionou um estímulo cognitivo-motor novo e distinto daqueles presentes no repertório de mobilidade corporal previamente adquirido pelos jovens, por outro lado, a frequentação dos espaços acima elencados ensejou o acesso a uma multiplicidade de práticas de lazer. Mais que isso, no plano cultural, a multiplicação de interações sociais nestes vários locais significou uma ampliação dos contatos interculturais dos estudantes com outros segmentos da sociedade que adotam modos de vida em parte distintos dos seus próprios ${ }^{14}$.

\footnotetext{
11 O projeto de iniciação ao badminton foi implementado pelo SESC em múltiplos municípios do Rio de Janeiro, em escolas públicas, a partir do ano de 2014. As escolas cediam o espaço físico e os professores de Educação Física; o SESC, treinamento técnico e material esportivo.

12 Efeitos relatados pela equipe escolar e também registrados pelos pesquisadores noutras escolas, onde o projeto Badminton foi implantado.

13 Os objetos (incluindo os objetos esportivos) possuem efeitos formadores que são inteiramente ignorados pela maior parte das teorias da educação. Como sugerem Mary Douglas e Baron Isherwood (2009), os objetos não são apenas bens de consumo, eles são também veículos de informação (e não apenas das informações técnicas para a sua produção, neles objetivadas, senão também de informações sociais, vinculadas aos usos a eles atribuídos pelas tradições; eles são, nesse sentido, mediadores culturais). De modo consonante, ArjunAppadurai (1986) trata os objetos (inclusive sob a forma de mercadoria) como "meios de conhecimento". E acrescenta: "Commodities represent vary complex social forms and distributions of knowledge" (APPADURAI, p. 40).

14 Também a este respeito, importa salientar que é conhecida a dinâmica sociológica segundo a qual um circuito de mobilidade geográfica direcionado deliberadamente a um objetivo específico (por exemplo, à participação em um evento esportivo) supõe, para além deste objetivo restrito, múltiplas oportunidades de experiências culturais. Na Antropologia esta perspectiva sobre a mobilidade geográfica iniciou-se já em Malinowski (1984), em seu relato de 1922 sobre a instituição do Kula, entre sociedades do Pacífico Ocidental. Para um debate contemporâneo sobre a mobilidade e sua positividade sociocultural ver Guedes (2011).
} 


\section{CONCLUSÃO}

Como o leitor pôde testemunhar, este artigo constituiuma avaliação preliminar da implementação deum projeto de extensão universitária. Do que foi relatado, no entanto, uma reflexão permanece incompleta. A saber, os efeitos da segregação urbana sobre os próprios coordenadores do projeto em sua tentativa de cooperar com o esforço coletivo para combater a segregação.

A escassez de espaços de lazer disponíveis no bairro Terra Nova impôs um poderoso óbice à continuidade do projeto, naquele território, quando fomos impossibilitados de atuar no campinho de várzea. Transferir as atividades para a "churrasqueira" significaria subtrair tempo de práticas de sociabilidade dos moradores adultos que têm aquele salão social como lócus fundamental. Simultaneamente, o subterfúgio da crise financeira do Estado do Rio de Janeiro impôs limites econômicos também sobre a UERJ e, por conseguinte, para a atuação dos coordenadores do projeto; limites que se traduziram, inclusive, em redução de suas possibilidades de mobilidade urbana. Por vezes, os alunos do projeto não tinham como sair do bairro Terra Novae os coordenadores, com salários atrasados,não conseguiam se transportar até lá.

Transferimo-nos para a escola do bairro São Geraldo, também segregado, mas algo mais próximo do centro da cidade, deixando parte dos alunos do bairro Terra Nova certamente mais frustrada que nós mesmos - já que a maioria não tinha como se transportar até o novo local. O fechamento da UERJ, ao longo de quase todo o processo relatado, impossibilitou o aproveitamento da infraestrutura de lazer do campus Nova Friburgo, sem manutenção e condições de uso. Não fosse a colaboração do SESC, permaneceríamos, a professora de Educação Física da escola em foco e nós mesmos, com condições muito limitadas de atuação. No que se seguiu ao início do projeto Badminton, pudemos levar a curso um trabalho de articulação entre a realização das escolinhas, na esfera local, e a vida lúdica e esportiva mais geral da cidade, materializada em eventos esportivos. Tendo no horizonte de nossos objetivos a tematização do direito à cidade, conseguimos ampliar a escala de uso dos equipamentos urbanos de lazer, por parte dos alunos, por meio do aproveitamento de um calendário esportivo já existente na cidade. $E$, no entanto, 0 intento de aproveitar também eventos ligados aos gêneros artísticos permaneceirrealizado em decorrência da necessidade de pagamento financeiro para acessá-los.

Em suma, o balanço do processo de interiorização da extensão ora relatado indica que a proposição de um projeto de lazer extrínseco ao cotidiano social de um determinado território constituiu uma iniciativa problemática e mesmo perigosa; as atividades levadas a curso no bairro Terra Nova, repita-se, culminaram em um fracasso provavelmente frustrante para os jovens. Nossas conclusões preliminares sugerem antes que maiores chances de êxito emergem quando as ações extensionistas buscam cooperar com práticas em curso, protagonizadas pela própria comunidade. Isto nos ajuda a interpretar o malogro das intervenções, no bairro Terra Nova, bem como o relativo êxito da atuação cooperativa triangular escola pública/SESC/UERJ, no bairro São Geraldo.

Finalmente, há que se enfatizar o obstáculo, difícil de transpor, objetivado na precarização material dos equipamentos públicos de lazer dos territórios urbanos segregados. Há um dito que se consolidou no senso comum acadêmico, segundo o qual o trabalho do 
educador não pode ser negligenciado por conta da insuficiência de infraestrutura. Nossa vivência como coordenadores/etnógrafos no projeto de extensão aqui apresentado nos sugere a necessidade de considerar seriamente as ambiguidades deste postulado: a atuação dos profissionais da educação, do lazer, das artes, do esporte e da animação cultural, em geral, por prodigiosa que seja, não suprime os efeitos limitantesensejados por uma materialidade marcada pela escassez.

\section{REFERÊNCIAS}

ALVES, Flávio Soares. A dança 'em-cena' o Outro: prerrogativas para uma educação estética a partir do processo criativo. Movimento, v. 15, n. 3, p. 333-354, 2009.

APPADURAI, Arjun. The Social Life of Things: Commodities in Cultural Perspective. Cambridge: Cambridge University, 1986.

AZEVEDO, Fernando de. A poesia do corpo ou a gymnastica escolar: sua história e seu valor. Belo Horizonte: Imprensa Oficial do Estado de Minas Gerais, 1915.

BETTI, Mauro. Educação física esociedade: a educaçãofísicana escola brasileira de $1^{\circ}$ e $2^{\circ}$ graus. SãoPaulo: Movimento, 1991.

BERARDI, Franco. What does Cognitariat Mean? Work, Desire and Depression.Cultural Studies Review, v. 11, n. 2, p.57-63, Sep. 2005.

BRACHT, Valter et al. Metodologia do ensino de educação física. São Paulo: Cortez, 1992.

DAOLIO, Jocimar. Da cultura do corpo. São Paulo: Papirus, 1995.

DOUGLAS, Mary; ISHERWOOD, Baron. 0 mundo dos bens: para uma antropologia do consumo. Rio de Janeiro: Editora UFRJ, 2009.

ESPÍRITO SANTO, Wecisley Ribeiro do. Confrontando escalas: contribuições da etnografia para a teoria social sobre movimentos populares urbanos.Enfoques, v. 1, n. 14, p. 35-48, 2015.

ESPÍRITO SANTO, Wecisley Ribeiro do. Notas etnográficas de uma tragédia em Nova Friburgo. Tensões Mundiais, v. 8, n. 15, p. 259-279, 2012.

ESPÍRITO SANTO, Wecisley Ribeiro do; CUPOLILLO, Amparo Villa. Teoria e prática pedagógica em educação física: um estudo sob a perspectiva da pesquisa participante.Revista da Universidade Rural, SérieCiências Humanas, v. 27, n. 1/2, p. 99-105, jan.-dez. 2005.

FATTORELLI, Maria Lucia. Auditoria cidadã da dívida dos estados. Brasília: Inove, 2013.

FREIRE, João Batista Freire. Educaçãodecorpointeiro:teoria e prática da educação física. São Paulo. Editora: Scipione, 1989.

GUEDES, André Dumans. 0 Trecho, as Mães e os Papéis: Movimentos e Durações no Norte de Goiás. 2011. 488 f.Tese (Doutorado) -Programa de pós-graduação em Sociologia e Antropologia.Rio de Janeiro, 2011. 
HARVEY, David. Cidades Rebeldes: do direito à cidade à revolução urbana. São Paulo: Martins Fontes, 2014.

HARVEY, David. The right to the city. New Left Review, n.53, Sept./Oct. 2008. Disponivel em:<https://newleftreview.org/l//53/david-harvey-the-right-to-the-city $>$. Acesso em: 14 fev.2018.

HUIZINGA, Johan. Homo Ludens: a Study of the Play-element in Culture. Boston: Beacon, 1955.

JACOBS, Jane. Morte e vida das grandes cidades. São Paulo: Martins Fontes, 2011.

KUNZ, Eleonor. Transformação didático-pedagógica do esporte. ljuí: Unijuí, 1994.

LEFEBVRE, Henri. La production de l'espace. Paris : Anthropos, 2000.

LEFEBVRE, Henri.Le droit à la ville. Paris: ÉditionsAnthropos, 1968.

MALINOWSKI, Bronislaw Kasper. Argonautas do pacífico ocidental: um relato do empreendimento e da aventura dos nativos nos arquipélagos da Nova Guiné Melanésia. São Paulo: Abril Cultural, 1984.

MARICATO, Ermínia.É a questão urbana, estúpido! In: MARICATO, Ermínia et al.Cidades Rebeldes: Passe Livre e as manifestações que tomaram as ruas do Brasil. São Paulo: Boitempo: Carta Maior, 2013.p. 19-26.

MARLEAU-PONTY, Maurice. Marxismo e filosofia. São Paulo: Abril Cultural, 1980.(Coleção Os pensadores).

MELO, Victor Andrade de. Esporte, lazer e artes plásticas: diálogos. Rio de Janeiro: Apicuri, 2009.

OLIVEIRA, Vitor Marinho. 0 esporte pode tudo. São Paulo: Cortez, 2010.

PANDOLFI, Dulce; ESPÍRITO SANTO, Wecisley Ribeiro do. Movimentos sociais urbanos e esfera pública questões para o debate. In: LEITE LOPES, José Sergio; HEREDIA, Beatriz (Org.) Movimentos sociais e esfera pública: o mundo da participação. Rio de Janeiro: Secretaria Geral da Presidência da República/Colégio Brasileiro de Altos Estudos, 2014.p. 157-186.

PIAGET, Jean. A epistemologia genética.São Paulo: Victor Civita, 1983.(Coleção Os Pensadores).

REIS, Leôncio José de Almeida; CACICHIOLLI, Fernando Renato. Resenha do livro "A Animação Cultural: conceitos e propostas" de Victor Andrade de Melo.Movimento, v. 15, n. 3, p. 357-371, 2009.

RETONDAR, Jeferson José Moebus. Imaginário e representações sociais: corpo, educação física, cultura e sociedade. Maceió: EDUFAL, 2007.

SCHILLER, Friedrich. A Educação estética do homem. São Paulo: lluminuras, 2002.

SOARES, Carmen Lúcia; MADUREIRA, José Rafael. Educação física, linguagem e arte: possibilidades de um diálogo poético do corpo. Movimento,v. 11, n. 2, p. 75-88, 2005. 
